A. W. J. LOGAN, S. J. SPRAGUE, R. W. FOSTER, L. B. MARX, V. GARZYA, M. S. HALlSide, A. L. THOMPSON, J. W. BURTON* (UNIVERSITY OF OXFORD AND GLAXOSMITHKLINE,

HARLOW, UK)

Diastereoselective Synthesis of Fused Lactone-Pyrrolidinones; Application to a Formal Synthesis of

(-)-Salinosporamide A

Org. Lett. 2014, 16, 4078-4081.

\title{
Manganese-Mediated Coupling Approach to Fused Lactone-Pyrrolidinones
}

Gategory

Synthesis of

Heterocycles

Key words

lactones

pyrrolidinones

radical cyclization

manganese-

mediated coupling

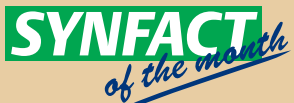

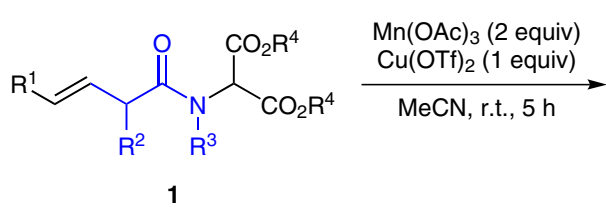

$\mathrm{R}^{1}=\mathrm{H}, \mathrm{Ph}$

$\mathrm{R}^{2}=\mathrm{H}, \mathrm{Me}, \mathrm{Et}, i-\mathrm{Pr}, n-\mathrm{Bu}, \mathrm{CH}_{2} \mathrm{CCH}$, allyl, $\mathrm{Bn},\left(\mathrm{CH}_{2}\right)_{2} \mathrm{OBn}$ $R^{3}=H, P M B$

$\mathrm{R}^{4}=\mathrm{Me}, \mathrm{Et}, t-\mathrm{Bu}$

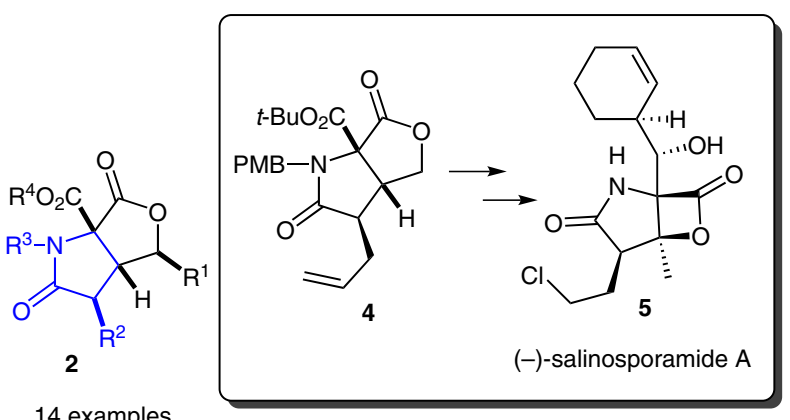

14 examples $43-87 \%$ yield

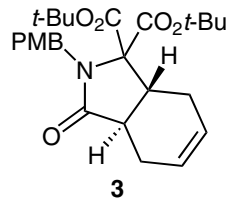

Significance: The diastereoselective synthesis of a fused lactone-pyrrolidinone core $\mathbf{2}$ from enamidomalonates 1 via a manganese-mediated coupling is reported. After optimization, the diastereocontrol of this reaction was shown to be the most efficient at room temperature, and the structure of the major diastereomer was established by $\mathrm{X}$-ray analysis. A series of $\alpha$-substituted enamidomalonates $1(R=P h)$ gave the cyclized products 2 in moderate to good yield and good diastereoselectivity. In case of enamidomalonates bearing terminal olefins, the cyclization was achieved using para-methoxybenzyl-protected amines in moderate to good yields. A variety of dialkyl malonates were also well tolerated. The trans-fused bicyclic alkene $\mathbf{3}$ was formed when allyl-substituted amides were subjected to the reaction conditions. However, the formation of this byproduct can be minimized by increasing the amount of copper. The present methodology was applied to the enantioselective synthesis of the natural product $\mathbf{5}$.
Comment: The fused lactone-pyrrolidinone core is present in a range of natural products which exhibit biological properties such as antitumor activities (e.g., proteasome inhibitors: A. Rentsch et al. Angew. Chem. Int. Ed. 2013, 52, 5450; E. O. Onyango et al. Angew. Chem. Int. Ed. 2007, $46,6703)$. In this report, a mild approach to this fused scaffold under good diastereoselective control was developed. The reaction shows a good substrate scope and phenyl-substituted as well as terminal alkenes were suitable substrates. The starting materials were easily prepared by the coupling of 2-aminomalonate with the corresponding carboxylic acid, although in some cases a multistep synthesis was required. The methodology was used to generate intermediate $\mathbf{4}$ in the synthesis of the natural product (-)-salinosporamide $\mathrm{A}$. 